\title{
Whether immediate frozen-thawed embryo transfer improves IVF outcome in non-elective freeze all policy
}

\author{
Loris Marin, Amerigo Vitagliano \\ Department of Women's and Children's Health, University of Padua, Salus Pueri, Padova, Italy \\ Correspondence to: Amerigo Vitagliano, MD. Department of Women's and Children's Health, University of Padua, Salus Pueri, Via Giustiniani, 3, \\ 35128 Padova PD, Italy. Email: amerigovitagliano.md@gmail.com. \\ Provenance and Peer Review: This article was commissioned by the editorial office, Annals of Translational Medicine. The article did not undergo \\ external peer review. \\ Comment on: Huang J, Lu X, Xie Q, et al. Timing of frozen-thawed embryo transfer after controlled ovarian stimulation in a non-elective freeze-all \\ policy. Ann Transl Med 2019;7:752.
}

Submitted Apr 19, 2020. Accepted for publication May 09, 2020.

doi: 10.21037/atm-2020-97

View this article at: http://dx.doi.org/10.21037/atm-2020-97

With the spread of vitrification techniques, the survival rate after thawing of embryos rapidly increased, reaching up to $90 \%$ for vitrified blastocysts (1). As a result of the advances in embryology laboratory techniques, the "segmentation" of in vitro fertilization (IVF)-embryo transfer cycles has been gradually introduced in the common practice as an alternative to fresh IVF for the protection of woman's health and to improve the chances of implantation (2).

Non-elective freeze all policy is currently indicated in case of unforeseeable complications occurring during controlled ovarian stimulation (COS) (e.g., unexpected hyper-response, hyperprogesteronemia, endometrial abnormalities) or before embryo transfer (i.e., patients' fever and other illnesses). The principal question that remains unanswered concerns the optimal timing of frozen-thawed embryo transfer (FET) after COS. In this respect, the study by Huang et al. (3) heats up the debate on the possible advantages of immediate FET following non-elective freeze all cycles.

In their retrospective study, the authors included 2,998 patients who underwent their first FETs after the first COS cycles using the non-elective freeze-all strategy. Patients were divided into the "immediate" group (i.e., FET performed within the first menstrual cycle after COS), and the "delayed" group where FET started after one or more menstrual cycles following COS. As a statistical solution to the problem of endogeneity between groups, the authors used the propensity score adjustment of confounders, thereby increasing between group comparability. After confounders adjustment, delayed FET after COS was associated with significantly decreased chances of clinical pregnancy (OR: 0.46-0.94), ongoing pregnancy (OR: 0.42-0.84) and live birth (OR: 0.42-0.85) than immediate transfer, as well as with higher risk of miscarriage (OR: 1.05-8.06).

These interesting findings upon superiority of immediate transfer compared to delayed transfer were in line with one previous study (4), but contradicted other studies (5-10) that reported not significant differences between immediate and postponed embryo transfer. However, we cannot make direct inferences between studies as they applied different methodology (including differences in the protocols adopted and time intervals between oocyte retrieval and FET), and included patients with different characteristics.

To the credit of Huang et al. (3), theirs was the largest cohort size among the studies on this topic. Moreover, the use of propensity score matching may have minimized the selection bias over conventional multivariable regression techniques, therefore providing robustness to their results. Although the results were exciting, the underlying mechanism for the association between earlier timing of FET and higher success at IVF need to be further investigated. Basing on the findings of the study by Huang et al. (3), it may be speculated that COS leaves a transient hormonal footprint with positive effects on endometrial receptivity. In this respect, the persistence of active 
corpora lutea following COS could enhance the circulating concentrations of several ovarian hormones, such as relaxin, during FET cycle (11). Alternatively, supraphysiologic hormonal stimulation during COS may positively modulate the expression of specific endometrial genes during the following menstrual cycle (12), similarly to what observed in women after endometrial mechanical stimulation $(8,13)$.

The findings by Huang et al. (3) are intriguing but not definitive. Observational data, even though analyzed with statistically efficient techniques, need to be confirmed by randomized controlled trials for proving cause-and-effects relationships between two phenomena. Therefore, future randomized controlled trials, with strict inclusion criteria and rigorous methodology, are urgently needed.

Thanks to the efforts of Huang et al. from now on, immediate FET after COS can be considered as a valuable alternative to delayed FET. Until solid evidence will be available, physicians are advised to schedule FET based on clinical circumstances and after comprehensive patients' consultation.

\section{Acknowledgments}

Funding: None.

\section{Footnote}

Conflicts of Interest: Both authors have completed the ICMJE uniform disclosure form (available at http://dx.doi. org/10.21037/atm-2020-97). The authors have no conflicts of interest to declare.

Ethical Statement: The authors are accountable for all aspects of the work in ensuring that questions related to the accuracy or integrity of any part of the work are appropriately investigated and resolved.

Open Access Statement: This is an Open Access article distributed in accordance with the Creative Commons Attribution-NonCommercial-NoDerivs 4.0 International License (CC BY-NC-ND 4.0), which permits the noncommercial replication and distribution of the article with the strict proviso that no changes or edits are made and the original work is properly cited (including links to both the formal publication through the relevant DOI and the license). See: https://creativecommons.org/licenses/by-ncnd/4.0/.

\section{References}

1. Rienzi L, Gracia C, Maggiulli R, et al. Oocyte, embryo and blastocyst cryopreservation in ART: systematic review and meta-analysis comparing slow-freezing versus vitrification to produce evidence for the development of global guidance. Hum Reprod Update 2017;23:139-55.

2. Blockeel C, Campbell A, Coticchio G, et al. Should we still perform fresh embryo transfers in ART? Hum Reprod 2019;34:2319-29.

3. Huang J, Lu X, Xie Q, et al. Timing of frozen-thawed embryo transfer after controlled ovarian stimulation in a non-elective freeze-all policy. Ann Transl Med 2019;7:752.

4. Higgins C, Healey M, Jatkar S, et al. Interval between IVF stimulation cycle and frozen embryo transfer: Is there a benefit to a delay between cycles? Aust N Z J Obstet Gynaecol 2018;58:217-21.

5. Santos-Ribeiro S, Siffain J, Polyzos NP, et al. To delay or not to delay a frozen embryo transfer after a failed fresh embryo transfer attempt? Fertil Steril 2016;105:1202-7.e1.

6. Kaye L, Marsidi A, Rai P, et al. Frozen blastocyst transfer outcomes in immediate versus delayed subsequent cycles following GnRH agonist or hCG triggers. J Assist Reprod Genet 2018;35:669-75.

7. Lattes K, Checa MA, Vassena R, et al. There is no evidence that the time from egg retrieval to embryo transfer affects live birth rates in a freeze-all strategy. Hum Reprod 2017;32:368-74.

8. Ozgur K, Bulut H, Berkkanoglu M, et al. Frozen embryo transfer can be performed in the cycle immediately following the freeze-all cycle. J Assist Reprod Genet 2018;35:135-42.

9. Bourdon M, Santulli P, Maignien C, et al. The interval between oocyte retrieval and frozen-thawed blastocyst transfer does not affect the live birth rate and obstetrical outcomes. PLoS One 2018;13:e0206067.

10. He Y, Zheng H, Du H, et al. Delayed frozen embryo transfer failed to improve live birth rate and neonatal outcomes in patients requiring whole embryo freezing. Reprod Biol Endocrinol 2020;18:1.

11. Conrad KP, Baker VL. Corpus luteal contribution to maternal pregnancy physiology and outcomes in assisted reproductive technologies. Am J Physiol Regul Integr Comp Physiol 2013;304:R69-72.

12. Haouzi D, Assou S, Mahmoud K, et al. Gene expression profile of human endometrial receptivity: comparison between natural and stimulated cycles for the same 
patients. Hum Reprod 2009;24:1436-45.

13. Vitagliano A, Di Spiezio Sardo A, Saccone G, et al.

Endometrial scratch injury for women with one or more previous failed embryo transfers: a systematic review and meta-analysis of randomized controlled trials. Fertil Steril 2018;110:687-702.e2.

Cite this article as: Marin L, Vitagliano A. Whether immediate frozen-thawed embryo transfer improves IVF outcome in nonelective freeze all policy. Ann Transl Med 2020;8(16):979. doi: 10.21037/atm-2020-97 